\section{Successful Switch of Patients with Rheumatoid Arthritis Developing Anti-tumor Necrosis Factor (anti-TNF)-induced Lupus to Another Anti-TNF Agent}

To the Editor:

We read with interest the recent letter ${ }^{1}$ and editorial ${ }^{2}$ discussing anti-tumor necrosis factor (anti-TNF)-induced lupus requiring cessation of therapy for disease resolution. A lack of published experience of successful TNF inhibitor switching ( 8 total cases in the literature) causes concern for rheumatologists faced with this clinical scenario. We describe 2 more patients who successfully switched to different TNF inhibitor after developing anti-TNF-induced lupus.

Patient 1. A 43-year-old woman with a 15-year history of seropositive rheumatoid arthritis (RA) achieved remission when treated with adalimumab $50 \mathrm{mg}$ biweekly 8 years ago. Adalimumab was increased to $50 \mathrm{mg}$ weekly when she developed an arthritis flare. Her arthritis worsened and she developed severe pleuritis but no other lupus features. Laboratory investigations revealed anti-dsDNA antibodies that were not present in her preadalimumab antibody profile and persistence of anti-SSA antibodies that were present prior to adalimumab. A diagnosis of adalimumab-induced lupus was made and adalimumab was discontinued. Her symptoms resolved while taking prednisone $60 \mathrm{mg}$ daily. One month later, she was asymptomatic on a tapering course of prednisone. Her antibody profile at that time remained positive for anti-SSA antibodies but was negative for anti-dsDNA antibodies. She had a flare of RA off prednisone; therefore, she was treated with etanercept $25 \mathrm{mg}$ twice weekly. The disease went into remission and has remained so for the past 4 years. Her antibody profile remains positive for anti-SSA antibodies and negative for anti-dsDNA antibodies.

Patient 2. A 58-year-old woman with a 20-year history of seropositive RA was treated with infliximab $3 \mathrm{mg} / \mathrm{kg}$ in addition to leflunomide $20 \mathrm{mg} /$ day. Ten weeks after starting infliximab she developed oral ulcers and increased joint symptoms with, active synovitis on examination. Laboratory investigations revealed anti-dsDNA antibodies that were not present in her preinfliximab antibody profile. Her extractable nuclear antigen (ENA) profile was negative. She was diagnosed with infliximab-induced lupus and the infliximab was discontinued. She was maintained on leflunomide 20 mg/day. Her joint symptoms improved and oral ulcers resolved 2 months later. A repeat antibody profile showed that her ENA remained negative and her anti-dsDNA antibodies were negative. Her disease remained under control for 3 years taking leflunomide. She subsequently developed a disease flare and etanercept $25 \mathrm{mg}$ twice weekly was added, with resolution of her synovitis. Two and a half years later she remains asymptomatic and her ENA and anti-dsDNA antibody profiles are negative.

Treatment of patients with active RA who have had anti-TNF-induced lupus with a second TNF inhibitor should be monitored closely. Anti-TNF-induced lupus may be a class effect, as it has been reported to occur with all forms of this therapy. It is recognized that antinuclear antibodies occur in association with anti-TNF therapies but anti-TNF-induced lupus is uncommon. In one study of RA patients treated with one of 3 anti-TNF therapies, infliximab, etanercept, and adalimumab were all shown to cause the development of anti-nucleosome antibodies, antibodies that have a role in the diagnosis and followup of patients with systemic lupus erythematosus ${ }^{3}$. However, the investigators comment that the development of anti-TNF-induced lupus is uncommon with these agents. In another study over $50 \%$ of infliximab-treated patients and $10 \%$ of etanercept-treated patients developed anti-dsDNA antibodies, suggesting differences in immunogenicity between the drugs ${ }^{4}$. This observation is of interest in view of the data reported in another study of anti-TNF-induced lupus that shows infliximab is associated with anti-TNF-induced lupus more frequently than etanercept or adalimumab ${ }^{5}$.

Anti-TNF-induced lupus differs from the classic drug-induced lupus in that it is characterized by a greater frequency of skin involvement, the presence of anti-dsDNA antibodies, and the lack of anti-histone antibodies.
Affected patients have also been reported to have renal involvement, an uncommon finding in classic drug-induced lupus ${ }^{5}$.

Our experience in successfully switching from an anti-TNF therapy that caused anti-TNF-induced lupus to another anti-TNF provides further data for rheumatologists to manage these challenging patients. Our patients were successfully switched from a monoclonal antibody to etanercept with sustained RA disease control and no recurrence of anti-TNF-induced lupus. Our experience mirrors that of similar successful switches to another anti-TNF therapy $6,7,8,9$; however, the cases presented by Soforo, et $a l^{1}$ remind us to use caution in performing this switch. Treatment choices will inevitably depend upon how severe the initial features of anti-TNF-induced lupus were.

A recent case report suggests that anti-SSA antibodies in the pretreatment serum of patients may increase the risk of developing anti-TNF-induced lupus ${ }^{10}$. Perhaps these cases have a closer immunological relationship to SLE than the ENA-negative patient. Although Patient 1 had anti-SSA antibodies she was able to switch successfully to a second anti-TNF therapy without developing anti-TNF-induced lupus. The decision to switch to another TNF inhibitor in the event of anti-TNF-induced lupus requires close clinical and serological review of the patient.

CARRIE YE, MD; DALTON SHOLTER, MD, University of Alberta, Edmonton; LIAM MARTIN, MD, University of Calgary, Foothills Hospital, Calgary; STEPHANIE KEELING, MD, University of Alberta, 562 Heritage Medical Research Center, Edmonton, Alberta, Canada. Address correspondence to Dr. Keeling;

E-mail: stephanie.keeling@ualberta.ca

\section{REFERENCES}

1. Soforo E, Baumgartner M, Francis L, Allam F, Phillips PE, Perl A. Induction of systemic lupus erythematosus with tumor necrosis factor blockers [letter]. J Rheumatol 2010;37:204-5.

2. Jacob N, Jacob CO. On anti-tumor necrosis factor-induced systemic lupus erythematosus. J Rheumatol 2010;37:3-5.

3. Benucci M, Saviola G, Baiardi P, Cammelli E, Manfredi M. Anti-nucleosome antibodies as prediction factor of development of autoantibodies during therapy with three different TNF- $\alpha$ blocking agents in rheumatoid arthritis. Clin Rheumatol 2008;27:91-5.

4. DeRycke L, Baeten D, Kruithof E, Van de Bosch F, Veys EM, Dekeyser F. Infliximab, but not etanercept, induces IgM anti-double-stranded DNA antibodies as main antinuclear reactivity: biologic and clinical implications in autoimmune arthritis. Arthritis Rheum 2005;52:2192-201.

5. Costa MF, Said NR, Zimmerman B. Drug-induced lupus due to anti-tumour necrosis factor alpha agents. Semin Arthritis Rheum 2008;37:381-7.

6. Luong J, Tan B, Buchanan R, Schachna L. Tumour necrosis factor inhibitor-related lupus: safety of switching agents. Clin Rheumatol 2010;29:551-3.

7. Wetter DA, Davis MD. Lupus-like syndrome attributable to anti-tumor necrosis factor alpha therapy in 14 patients during an 8-year period at Mayo Clinic. Mayo Clin Proc 2009;84:979-84.

8. Kocharla L, Mongey AB. Is the development of drug-induced lupus a contraindication for switching from one TNF alpha inhibitor to another? Lupus 2009;18:169-71.

9. De Bandt M, Sibilia J, Le Loet X, Prouzeau S, Fautrel B, Marcelli C, et al. Systemic lupus erythematosus induced by anti-tumour necrosis factor alpha therapy: a French national survey. Arthritis Res Ther 2005;7:545-51.

10. Cavazzana I, Bobbio-Pallavicini F, Franceschini F, Bazzani C, Ceribelli A, Bravi E, et al. Anti-TNF-alpha treatment in rheumatoid arthritis with anti-Ro/SSA antibodies. Analysis of 17 cases among a cohort of 322 treated patients. Clin Exp Rheumatol 2007;25:676-83.

J Rheumatol 2011;38:6; doi:10.3899/jrheum.100830

Personal non-commercial use only. The Journal of Rheumatology Copyright @ 2011. All rights reserved. 